\title{
Intraflagellar Transport Protein 88 Homolog
}

National Cancer Institute

\section{Source}

National Cancer Institute. Intraflagellar Transport Protein 88 Homolog. NCI Thesaurus. Code C128946.

Intraflagellar transport protein 88 homolog (833 aa, 94 kDa) is encoded by the human IFT 88 gene. This protein is involved in cilium and autophag osome assembly. 